\title{
Editorial
}

www.anatomy.org.tr

Received: March 28, 2015; Accepted: March 30, 2015

doi:10.2399/ana.15.002

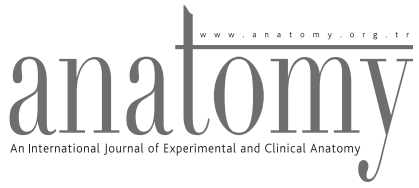

\section{A new chapter in Anatomy}

\author{
Gülgün Şengül \\ Editor-in-Chief; Department of Anatomy, Faculty of Medicine, Ege University, Izmir, Turkey \\ Anatomy 2015;9(1):iii @2015 Turkish Society of Anatomy and Clinical Anatomy (TSACA)
}

Anatomy is an expanding field in biological sciences, starting from the earlier works of gross anatomy, now developing at an unprecedented pace with huge advances in imaging, experimental techniques, cellular and molecular biology, and computational anatomy.

At this time, I am honored to take over as the new Editor-in-Chief of Anatomy, the official publication of The Turkish Society of Anatomy and Clinical Anatomy (TSACA). Starting with this issue, we will continue with new Editorial Board and Scientific Advisory Board members consisting of about a hundred leading scientists from different disciplines of anatomy worldwide.

Formerly an annual publication, the journal will now be published three times a year. Anatomy will continue to be a peer-reviewed journal publishing basic and clinical research concerning all aspects of anatomy. In addition to original articles, case reports and reviews, the journal will continue with 'Teaching Anatomy', 'Technical Note', 'Viewpoint', 'Historical View', 'Terminology Zone', 'Letters to the Editor' and 'Book Review' sections. We will be including new sections in the future issues such as 'Minisymposia'.

My vision for Anatomy is straightforward: to publish high-quality academic work and to provide a forum for rapid communication of original and pioneering anatomy research findings. Special consideration will be given to process and review manuscript submissions in a timely fashion, and to comply with ethical principles in publishing scientific research papers. My desire for Anatomy is to continue to excel and insightfully build for the future to provide a supreme venue for sharing outstanding anatomy work and serve the needs of the diverse community of anatomy researchers.

I would like to take this opportunity to extend my thanks to the founding editors of the journal, Professors Salih Murat Akkın and Hakan Hamdi Çelik for their efforts in establishing the journal, and to all former members of the Editorial Board and Scientific Advisory Board for their valuable contributions. Our former Editor-inChief Salih Murat Akkın will continue his support to our journal as Advising Editor. I believe, in the near future, Anatomy will have a highly regarded position amongst other journals of the field with the support of all its contributors.

Looking forward to sharing knowledge in this exciting field of science, Anatomy.

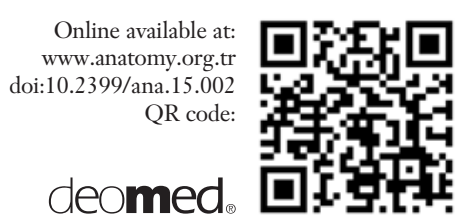

Correspondence to: Gülgün Şengül, MD Department of Anatomy, Faculty of Medicine, Ege University, Bornova, 35100, Izmir, Turkey e-mail: gulgun.sengul@gmail.com

Conflict of interest statement: No conflicts declared.

This is an open access article distributed under the terms of the Creative Commons Attribution-NonCommercial-NoDerivs 3.0 Unported (CC BY-NCND3.0) Licence (http://creativecommons.org/licenses/by-nc-nd/3.0/) which permits unrestricted noncommercial use, distribution, and reproduction in any medium, provided the original work is properly cited. Please cite this article as: Şengül G. A new chapter in Anatomy. Anatomy 2015;9(1):iii. 


\section{Curriculum vitae of the Editor-in-Chief}

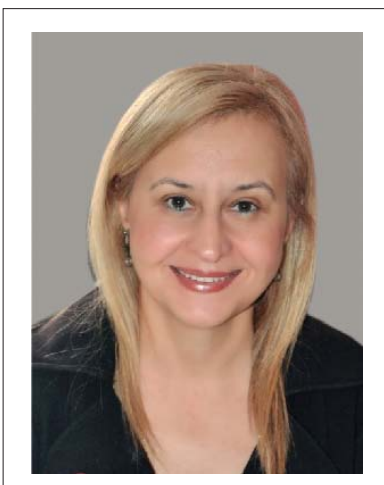

Gülgün Şengül, MD gulgun.sengul@gmail.com
Gülgün Şengül (MD) is a Professor of Anatomy in Ege University, School of Medicine, Izmir, Turkey. Her research field is neuroanatomy. She is one of the authors of the comprehensive spinal cord text book The Spinal Cord: A Christopher and Dana Reeve Foundation Text and Atlas (Elsevier, 2009). Her recent work Atlas of the Spinal Cord of the Rat, Mouse, Marmoset, Rhesus, and Human (Elsevier, 2013) comprises the first marmoset and rhesus monkey and human spinal cord atlases published. These provide a significant platform on which further spinal cord research can be built. She has also published spinal cord and brainstem chapters in the books The Mouse Nervous System (Elsevier, 2012), The Human Nervous System (Elsevier, 2012) and The Rat Nervous System (Elsevier, 2014) and manuscripts in the field of neuroanatomy. Dr. Şengül contributed as an advisor to the Allen Institute for Brain Science (Seattle, Washington) Spinal Cord Atlas Project and brainstem part of the Human Brain Project. 